\title{
A FRONTEIRA NA ESCOLA: imaginários e narrativas escolares em Foz do Iguaçu
}

\section{LA FRONTERA EN LA ESCUELA: imaginarios y narrativas escolares en Foz de Iguazú}

\author{
Raquel Maia Ferreira Arvelos ${ }^{1}$ \\ Laura Janaina Dias Amato ${ }^{2}$
}

Resumo: este artigo é o resultado de uma pesquisa de Iniciação Científica, vinculada ao projeto "Construção crítica do imaginário trinacional", que tem como objetivo analisar discursos de membros de comunidades escolares do ensino básico regular do município de Foz do Iguaçu, para compreender parte da formação do imaginário sobre a região trinacional. Neste trabalho apresentamos algumas reflexões, a partir de uma pesquisa qualitativa, de base interpretativista, sobre uma escola localizada próxima a fronteira com a Argentina. Tendo em vista que a escola é um lócus propício para a formação discursiva e imagética do sujeito, toma-se esse local e os sujeitos partícipes do mesmo, para buscar compreender como estes sujeitos apreendem a habitar e se constituir enquanto seres fronteiriços.

Palavras-chave: Imaginário; Educação; Fronteiras; Discursos.

Resumen: este artículo es el resultado de una investigación de Iniciación Científica, vinculada al proyecto "Construcción crítica de la imaginación trinacional", cuyo objetivo es analizar los discursos de los miembros de las comunidades escolares de la educación básica regular del municipio de Foz do Iguaçu, para comprender parte de la formación del imaginario sobre la región trinacional. En este artículo presentamos algunas reflexiones, desde una investigación cualitativa de base interpretativa, sobre una escuela ubicada cerca de la frontera con Argentina. Teniendo en cuenta que la escuela es un lugar propicio para la formación discursiva e imaginativa de los sujetos, considera este lugar y los participantes en él para comprender cómo estos sujetos aprenden a habitar y constituir como seres fronterizos. Palabras claves: Imaginario; Educación; Fronteras; Discursos.

\section{Introdução}

"Amar e mudar as coisas me interessa mais"

(BELCHIOR, Alucinação, 1976)

\footnotetext{
${ }^{1}$ Graduanda do Curso de História - Licenciatura, ex-bolsista remunerada da IC-FA, Pibis financiada pela Fundação Araucária - ILAACH, Instituto Latino-Americano de Arte, Cultura e Histórica UNILA; E-mail: raquel.arvelos@aluno.unila.edu.br.

${ }^{2}$ Docente/pesquisadora da área de Letras e Linguística - ILAACH, Instituto Latino-Americano de Arte, Cultura e Histórica - UNILA; E-mail: laura.amato@unila.edu.br.
} 
A cidade de Foz do Iguaçu está localizada na tríplice fronteira entre Paraguai, Argentina e Brasil, dividida pelo Rio Paraná e Iguaçu, que "separam" geograficamente e naturalmente os três países:

Figura 1 - Tríplice fronteira vista do espaço; printscreen da página oficial da Prefeitura Municipal de Foz do Iguaçu no Facebook

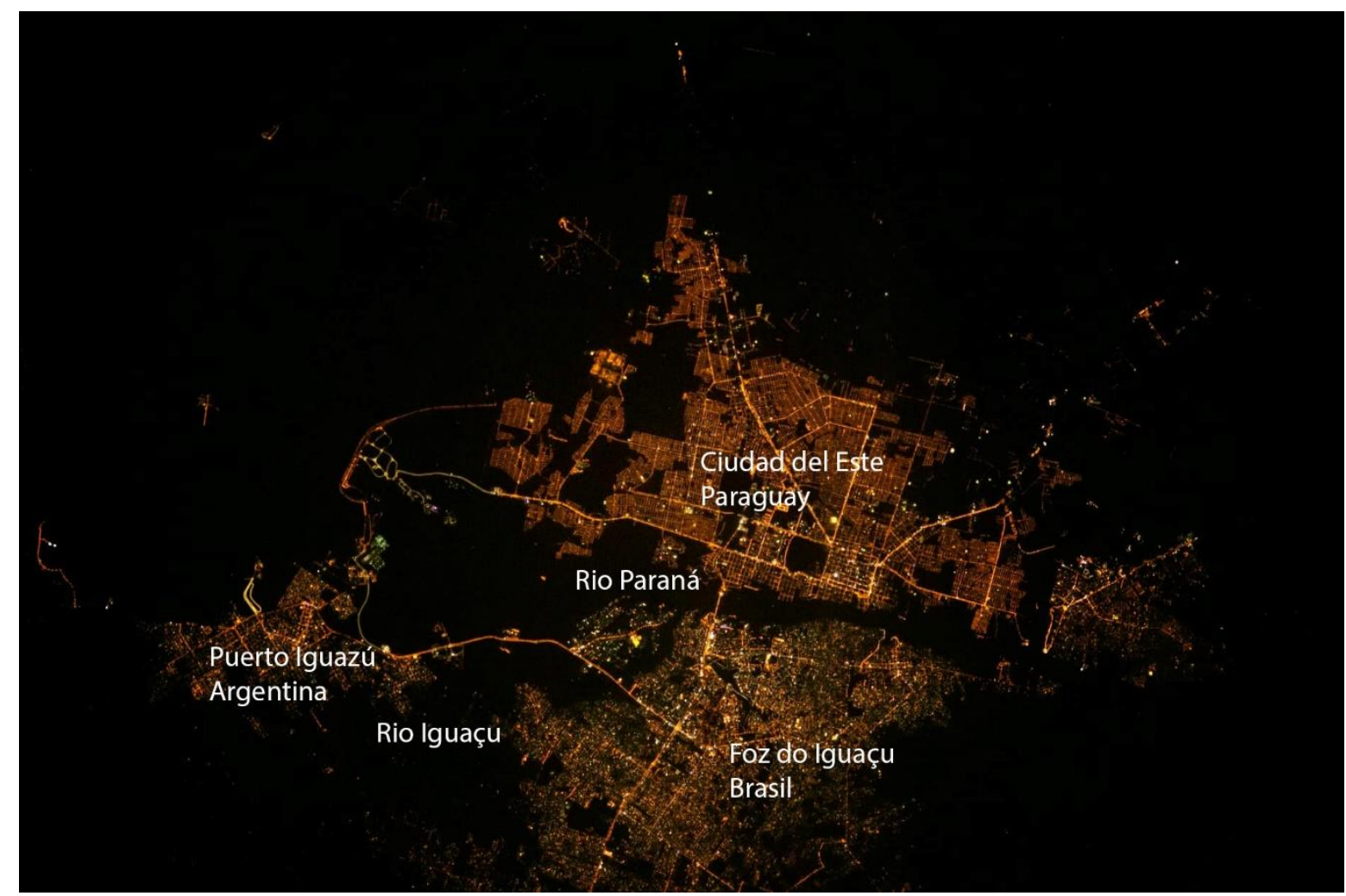

Fonte: https://www.facebook.com/prefeituradefozoficial/photos/a.1291232834323568/2336600783120096 Acesso em novembro de 2019.

Sobre um dos rios, Nara Oliveira (2012, p.31) declara que se não existisse (Rio Paraná), poderia ser considerado somente um território. Duas pontes também nos desenham concretamente o limite: a da Amizade (BRA-PY) e a da Fraternidade (BRA-ARG). Mas será que o nome que tais construções carregam dão conta da realidade vivenciada na região? Seria esta fronteira um espaço real de amizade e de fraternidade entre os povos fronteiriços?

Conforme aponta Oliveira (2012, p. 49) ser estrangeiro/a é uma marca daqueles/as que experienciam viver e/ou viajar por esta região - Brasil, Paraguai, Argentina, inclusive os/as habitantes fronteiriços/as não escapam desta condição. Por exemplo, quando frequentemente circulam pelos três países como se fossem bairros vizinhos, onde os laços familiares, afetivos e até mesmo de trabalho, atravessam e entrelaçam as localidades cotidianamente. Onde e quando, em tempos de paz, sobre essas relações, simbolicamente 
pode-se até sentir que as fronteiras nem mesmo existam.

Segundo José de Souza Martins (1997 apud MYSKIW, 2011), embora tentemos amenizar e neutralizar os conflitos da fronteira, a vida nesta região pode ser experienciada no seu limite. Enquanto a alteridade não se torna essencialmente política, entendendo o outro enquanto parte necessária e antagônica do nós, recorrentemente à ameaça, à insegurança e à instabilidade se instaura na fronteira concreta, as fronteiras de fato.

A escola, em sua essência, é um espaço atravessado por diferentes culturas e identidades que estão em constante ebulição, negociando constantemente suas existências. Elizabeth Macedo (2006) afirma que o currículo escolar já é em si um espaço-tempo fronteiriço, mas essa noção aqui se amplia quando se trata da escola posta em perspectiva, que está inserida em uma região geograficamente demarcada nos seus limites territoriais de Estado-Nação. A sua localização faz com que, muitas vezes, se intensifiquem as marcas da diferença.

Em Foz do Iguaçu, de acordo com o balanço de 2009 do Sistema de Cadastramento e Registro de Estrangeiros da Receita Federal (SINCRE), coabita-se 74 nacionalidades, diversidade essa que deveria se expressar na configuração de seus ambientes escolares, tendo em vista que esse registro está relacionado aos/as habitantes do município. Por isso, as escolas da região se tornam, elas mesmas, espaços de fronteira, de encontro e desencontros. E, para entender este processo, se e como esta diversidade é problematizada ou vista nas escolas, investigou-se currículos e narrativas escolares sobre como as pessoas (no caso, as docentes) se percebem e trabalham na fronteira.

A pesquisa foi realizada entre 2015 e 2018 em uma escola pública Municipal de Ensino Fundamental de Foz do Iguaçu ${ }^{3}$, localizada na região de uma ocupação circunscrita, espacial e significativamente, próximo ao Marco das Três Fronteiras ${ }^{4}$ de Foz do Iguaçu, entre Brasil, Argentina e Paraguai.

\footnotetext{
${ }^{3}$ Acordou-se sobre o sigilo ao nome das/os sujeitas/os escolares participantes, pois acreditamos que as problemáticas diagnosticadas não são simplesmente peculiares a esta específica escola. Entendese que existe uma problemática estrutural que permeia a sociedade, a política neoliberal, a colonialidade, o investimento e as políticas educacionais, assim como a formação das/os profissionais da educação.

4 "Um dos principais símbolos da região de Foz do Iguaçu, o Marco das Três das Fronteiras - obelisco erguido para celebrar a paz entre os povos - foi inaugurado em 20 de julho de 1903 e estabelece a soberania e o limite territorial do Brasil com a Argentina e o Paraguai" Disponível em: $<$ http://www.marcodastresfronteiras.com.br/marco-das-tres-fronteiras/historia $>$ Acesso em: $25 / 10 / 2017$.
} 
A escola atende estudantes das três nacionalidades ${ }^{5}$, a maioria em situação de vulnerabilidade socioeconômica como destacam as narrativas investigadas. Esses aspectos trazem inúmeros desafios para a comunidade escolar, seja pelas imagens que se constroem sobre as diferenças na fronteira, seja pelo desafio de educar na e para a "Pluralidade Cultural", como aponta o Projeto Político Pedagógico (PPP) da escola.

Em 2016, foi feito uma pesquisa aplicada, cujo objetivo era analisar a construção do imaginário sobre questões fronteiriças, entre estas, a questão da homogeneidade do sujeito, foco deste artigo. Cabe salientar que pesquisas de caráter aplicado visam conhecer práticas específicas para contribuir na solução de problemas locais, assim, vemos que as respostas dadas pelas docentes devem ser consideradas contingenciais, ou seja, respondem às necessidades específicas do contexto no qual elas atuam.

Para tanto, fizemos uma pesquisa qualitativa, de base interpretativista. Lakatos e Marconi (2003) apresentam a pesquisa qualitativa com um vínculo indissociável entre mundo objetivo e subjetividade do sujeito. Aqui temos um pesquisador que pode se tornar o próprio sujeito da pesquisa, transmutando o processo de significação através de uma abordagem indutiva.

Assim, utilizamos diversos procedimentos para a coleta e análise de dados: pesquisa documental, de campo e de cunho etnográfico. Utilizamos como motivador da análise, um questionário aplicado às docentes. Entre as perguntas, havia temas gerais que vinculavam ao viver e trabalhar na fronteira. Como parte das atividades da pesquisa, essas narrativas sobre a fronteira foram examinadas e contrastadas com os documentos que orientam as práticas escolares da escola, como o Projeto Político Pedagógico (PPP), os Parâmetros Curriculares Nacionais (PCN) e o Plano Municipal de Educação de Foz do Iguaçu, além de conversas informais estabelecidas com a comunidade escolar durante a realização de visitas à escola em 2017. Assim, pudemos triangular os dados documentais com as respostas obtidas no questionário e a observação no local, para examinar então como as narrativas produzidas, tanto nos documentos, quanto por docentes, compõem os imaginários de um contexto escolar em uma tríplice fronteira.

A triagem desta escola para aplicação do questionário, assim como a observação em sala de aula e realização desta pesquisa, foi justificada tanto por sua localidade, como citamos acima, quanto pela sua participação, desde 2005, no Programa Escolas Interculturais de

\footnotetext{
${ }^{5}$ Dado este levantado pelo Grupo de Pesquisa Linguagem, Política e Cidadania junto à Secretaria Municipal de Educação de Foz do Iguaçu. Nesta escola em especial, destaca-se uma grande presença de alunos provenientes do Paraguai.
} 
Fronteira (PEIF). Em linhas gerais, uma vez por semana, professoras da escola brasileira atravessavam a fronteira com a Argentina para ministrar aulas em Português a estudantes de outra escola participante do programa, enquanto professoras argentinas atravessavam a fronteira com o Brasil para ministrar aulas em Espanhol, isso era denominado como cruce. Portanto, acredita-se que essa instituição possui como forte característica um viés aberto e predisposto ao trabalho com a diversidade, assim como uma perspectiva intercultural forte e que perpassa o fazer pedagógico das docentes e dos docentes da instituição.

\section{A fronteira como currículo}

A fronteira e as relações de fronteira compõem o currículo das escolas de Foz do Iguaçu. Não de forma explícita ou formal, mas de modo velado, subentendido ou oculto, para usar a expressão de Michael Apple (2001 apud Paraskeva, 2002). Para o autor, o currículo oculto são normas e valores transmitidos pelas escolas não mencionados nos documentos e discursos oficiais.

Essa modalidade do currículo atravessa muito mais a subjetividade das pessoas envolvidas, a autonomia de quem o produz e a interpretação de quem recebe, do que a objetividade prescrita.

A educação e currículo não são, como Michael Apple salienta, magistérios neutros. Não acontecem num vazio cultural, político, ideológico, religioso e interseccionam-se diretamente nas dinâmicas de género, raça, classe e orientação sexual (PARASKEVA, 2002, p. 115).

Nesta perspectiva, o currículo oculto então se inter-relaciona com diversas questões do tempo-espaço, algumas vezes, de forma não muito harmoniosa. O currículo é a fronteira, o entre-lugar, pois precisa recorrentemente lidar, mediar, encontrar e desencontrar com as diferenças.

Penso o currículo como espaço-tempo de fronteira em que discursos globais e locais negociam sua existência (e inexistência posto que hibridizar significa renunciar à ideia de identidade baseada em raízes de qualquer natureza) (MACEDO, 2006, p. 107).

A fronteira, então, é uma região de muitos sentidos, como aponta Rosa Maria Medeiros:

Fronteiras não são linhas, mas muitas vezes são constituídas por espaços 
vazios, sem lugares e sem habitantes. A fronteira delimita o território, marca o espaço de sobrevivência, o espaço de força. É este o espaço defendido, negociado, cobiçado, perdido, sonhado cuja força afetiva e simbólica é forte (MEDEIROS, 2009, p. 218).

Desta forma, o currículo, neste trabalho, também é visto como este território de forças antagônicas, nas quais tanto a versão oficial (no caso, o PPP), quanto à oculta entram em disputa.

Para analisarmos as narrativas das professoras $^{6}$ envolvidas na pesquisa, também buscamos observar os currículos que permeiam a escola, a partir da leitura do PPP (currículo) da escola e da observação de práticas didáticas cotidianas (currículo oculto).

Neste sentido, ao analisarmos o PPP da escola, a localização da escola é especificada muito mais no sentido de estabelecer que tipo de moradores/as estão presentes naquele bairro, do que refletir sobre o espaço geográfico fronteiriço, como podemos exemplificar:

\begin{abstract}
Por se encontrar localizada num bairro considerado muito populoso, encontra dificuldades com relação à questão social. O bairro carece de toda uma infraestrutura, especialmente de saneamento básico. A população do bairro é extremamente carente. A escola está localizada num bairro de periferia, onde a população é bastante carente e vivem, em grande parte, de benefícios recebidos do governo (bolsa família, programa do leite, programa PETI, vale-gás, vale-alimentação). Desenvolvem o serviço informal (sacoleiros, catadores de papel, e outros). Observa-se em sala de aula que quase a totalidade dos alunos fazem parte dessa realidade. Isto faz com que se tornem acomodados, não buscam perspectivas melhores $\mathrm{e}$ deixam a responsabilidade maior da educação de seus filhos à escola, preocupando-se apenas com a garantia do benefício [grifos nossos] (PPP, 2015, p. 9).
\end{abstract}

O que poderia se caracterizar como específico da localização fronteiriça (sacoleiros) e periférica (bairro de pouca infraestrutura) é apresentado como lugar de pobreza, carência. O trecho acima não considera as questões socioeconômicas da clientela da escola como questões variantes de um processo de desigualdades históricas, despolitizando as poucas políticas que temos de equiparação social, além de excluir a escola desse papel social, como fonte de acesso a uma suposta igualdade social. Culpabiliza-se, dessa forma, a população de sua condição periférica e na fronteira entre mundos. Dessa forma, a acriticidade sobre a condição da periferia e a desvalorização da característica fronteiriça termina por privilegiar

\footnotetext{
${ }^{6}$ Optamos por manter no feminino, pois a classe docente é composta majoritariamente por mulheres. Além disso, as pessoas envolvidas nesta pesquisa em questão são todas do gênero feminino.
} 
determinadas culturas, hierarquizando, ocultando aquilo que lhe é particular. A escola, portanto, curriculariza um papel de assistência social, mesmo informando que é papel do governo e dos políticos garantirem um bem-estar social da comunidade, mas ao expor esses fatos, a escola se coloca como ponto focal necessário para que esta comunidade saia da sua inércia.

Além disso, a escola, apesar de citar ter como projeto integrado o PEIF, não cita os/as estudantes não-brasileiros/as matriculados/as e o papel da diversidade linguística e cultural presente nas salas de aula. Havendo muitos/as estudantes provenientes do Paraguai, a presença da língua e da cultura guarani na escola é inegável. O PEIF, da qual a escola faz parte, exclui, de certa forma, esta diversidade ao priorizar o bilinguismo entre espanhol e português, excluindo as línguas dos povos originários da terra, como o guarani, que é tão presente na tríplice fronteira, ontem e hoje, como nos aponta Nara Oliveira (2012):

\begin{abstract}
A história territorial de Ciudad del Este, Foz do Iguaçu e Puerto Iguazú foi semeada e cultivada sobre as bases da história do território Guarani, cuja cartografia indígena estava representada pela presença milenar daquele povo e por sua organização social, política, cultural e religiosa. Apesar das fronteiras demarcadas pelos Karai e das comunidades dizimadas pelo genocídio, o mapa Guarani Reta (2008) demonstra que vivem hoje quase 100 mil pessoas distribuídas em aproximadamente quinhentas aldeias nos três países (GRÜMBERG, 2008 apud OLIVEIRA, 2012, p. 23).
\end{abstract}

Para além dos próprios indígenas que utilizam sua língua materna, não é preciso ter ouvidos muito atentos para perceber a influência do guarani nos idiomas oficiais da fronteira. O guarani está sempre presente, embora isso muitas vezes é apagado, ocultado, na imposição de outros falares. Imposição que se expressa, por exemplo, na fala da coordenadora ${ }^{7}$ da escola, quando perguntado sobre estudantes que chegam à escola sem saber falar o português:

"Normalmente essas crianças que chegam, elas começam com uma semana, duas semanas, a pronúncia, a fala, elas conseguem entender, a maior dificuldade é a escrita, e daí essa escrita, daí tem né, acompanhamento dentro da sala, daí tem o reforço fora do turno dela, daí é isso que é feito... e ajuda dos pais né, que isso aí às vezes é difícil”.

Quando o processo de aculturação desejado é compreendido rapidamente, aprendese fácil o português. Parafraseando Fanon (2008), a língua é política e, através dela, é que internalizamos os significados da cultura. De certa forma, o amoldamento ao português é um epistemicídio, no "uso da língua como instrumento de dominação” (MIGNOLO, 2003, p.

\footnotetext{
${ }^{7} \mathrm{Na}$ escola há mais de uma coordenadora pedagógica.
} 
347), sem que se promova, dessa forma, uma efetiva interculturalidade ou a valorização entre os mais variados conhecimentos humanos. Contraditoriamente, o PPP da escola nos diz que a instituição aposta em uma educação inclusiva embora encontre muitas dificuldades para efetivá-la:

A inserção das tecnologias da informação no campo educacional, as políticas educacionais pautadas em competências e habilidades, a implementação legislativa das políticas pedagógicas inclusivas acabaram por criar uma demanda social para a qual a escola ainda não se encontrava preparada a uma nova concepção acerca dos alunos, hoje, denominados com necessidades educacionais especiais. As escolas também não tinham condições físicas de acesso para alunos sem autonomia, assim como não tinham condições materiais para realizar a inclusão digital e a inclusão escolar para todos os alunos, nem os professores tinham formação pedagógica para escolarizarem alunos com tamanha diversidade bio-psicosociocutural.

Se entendermos que os alunos com necessidades educativas especiais são todos aqueles com problemas de aprendizagem, os excluídos, as minorias étnicas, compreenderemos as dificuldades que as escolas veem encontrando para cumprir a legislação [grifos nossos] (PPP, 2015, p.10).

A diversidade que compreende os corpos e saberes escolares de e na fronteira é marcada como "especial”, não natural, não comum. Daí se compreende uma "lógica binária e seus efeitos: a hierarquia, a classificação, a dominação e a exclusão" (LOURO, G. L., 2001, p. 549). É “especial” quem não se encaixa no padrão que a instituição escolar exige e, por isso, a tendência é a de nos adaptar.

Estamos nós, repetidamente, reproduzindo a pedagogia do silêncio (GUSMÃO, 2013), silenciando determinadas culturas ao mesmo tempo em que tentam apagar as subjetividades importantes de nossas próprias diferenças. Mas "aprender a viver com o outro implica o direito que ele tem de continuar a ser o outro" (CONCEIÇÃO, 2016, p. 4). Desta forma, a diversidade deve ser pautada pela e na diferença, não devendo ser considerado excepcional ou especial. Como Chimamanda Adichie salienta: "a diferença é a realidade de nosso mundo" (ADICHIE, 2017, p. 76).

Quando não é vista como um problema, a fronteira é apresentada como algo extraclasse, externa à escola, conforme descrito no PPP $(2015$, p. 18) da escola, "os temas transversais são trabalhados da seguinte forma: através de projetos, feiras culturais, aulas culturais, passeios pedagógicos e palestras".

Os PCNs, no que diz respeito ao livro N.8 das Temáticas Transversais, sugere que tais assuntos sejam trabalhados no presente do dia a dia escolar, inclusive nas disciplinas: "A violência, a saúde, o uso dos recursos naturais, os preconceitos (...) temas devem ser tratados pela escola, ocupando o mesmo lugar de importância” (BRASIL, 1997, p. 23). 
A omissão ou o ocultamento da forma como a fronteira é trabalhada cotidianamente, como currículo, contribui para a negação das diferenças e para a perpetuação de todas as violências que advém desta negação. Pois, de nenhuma forma, negar apaga as diferenças.

De encontro e confronto com todas essas fronteiras e as contradições que a comportam, se afeta profundamente a autoestima dos corpos silenciados no espaço escolar.

Embora exista essa relação comum de aproximação e distanciamento decorrente do fazer parte da fronteira, é importante frisar que nosso olhar sobre essa fronteira e sobre Foz do Iguaçu é um olhar estrangeiro. Estar aqui nessa fronteira e em uma instituição que tem como missão a integração solidária da América Latina, nos faz refletir sobre nossa identidade multiterritorial (HAESBAERT, 2003), que perpassa vozes deslocadas e minoritarizadas pelo nosso gênero, pela nossa condição social e pela nossa sexualidade. No entanto, este dito olhar estrangeiro também é apresentado por Carvalho (2014 a), mesmo sendo ela foz do iguaçuense:

\footnotetext{
Por que durante o Ensino Fundamental nunca me foi apresentado um artista, uma obra ou uma prática cultural que dialogasse com as culturas vizinhas? Caetano Veloso (1978) já dizia que "Narciso acha feio o que não é espelho". Será, portanto, um problema de imagem? Identidade? Não posso afirmar que isso seja uma questão preocupante aos moradores da cidade, não sei se o meu vizinho, ao fixar no portão uma faixa com o nome da cidade onde cada letra simboliza um país da fronteira, pensa nisso tudo. Só sei que independente do discurso há uma ação, e essa revela subjetividades, escolhas e práticas, ou seja, uma cultura (CARVALHO, 2014a, p. 33).
}

Assim, acreditamos ser primordial pensar o currículo na e através das fronteiras, tanto epistemológicas, quanto territoriais. Pensar a territorialidade que permeia o cotidiano dos sujeitos escolares dentro e fora da instituição.

\section{A fronteira como ambiente}

Salientamos que todas as narrativas coletadas foram analisadas, neste trabalho, a partir das contribuições dos Estudos Culturais e Decoloniais, que permitem pensar o coexistir e o $[\operatorname{des}(\mathrm{re})]$ construir da identidade a partir do contato com o que afirmamos ser o nosso diferente. A perspectiva decolonial também prioriza a chamada epistemologias do Sul de Boaventura Souza Santos (TAVARES, 2009). Segundo Tavares (2009, p. 183):

A expressão Epistemologias do Sul é uma metáfora do sofrimento, da exclusão e do silenciamento de povos e culturas que, ao longo da História, foram 
dominados pelo capitalismo e colonialismo. Colonialismo, que imprimiu uma dinâmica histórica de dominação política e cultural submetendo à sua visão etnocêntrica o conhecimento do mundo, o sentido da vida e das práticas sociais. Afirmação, afinal, de uma única ontologia, de uma epistemologia, de uma ética, de um modelo antropológico, de um pensamento único e sua imposição universal.

Nesta perspectiva, coloca-se em evidência uma estrutura social hierarquizada através dos preceitos sociais, raciais, culturais e de gênero, além disso, há também os movimentos de resistência, nos quais as contradições do sujeito se desenvolvem, apresentando aspectos fortes do colonialismo nas práticas cotidianas. Segundo Chauí (1988, p. 35), “quem olha, olha de algum lugar”, portanto é este lugar que problematizamos e a partir de uma visão decolonial, privilegiando o pensamento do Sul e os discursos sobre estar e ser fronteiriço.

Em 2016, nove professoras que participaram do Programa Escolas Interculturais de Fronteira na escola investigada responderam um questionário aberto, com nove perguntas ${ }^{8}$ sobre como é viver e trabalhar na fronteira. As perguntas versavam sobre a opinião das docentes em relação ao território e sobre os habitantes deste. Além disso, perguntamos se elas já tiveram ou tinham à época, estudantes de nacionalidade argentina ou paraguaia e como lidavam com isso. Não é intuito deste trabalho fazer uma análise detalhada das respostas de todas as perguntas, pretendemos aqui trazer um panorama geral para discutir como a fronteira e seus sujeitos são invisibilizados nas narrativas educacionais - tanto no PPP, quanto na prática de sala de aula.

Em geral, para elas, habitar na fronteira é um espaço de diversidade, discurso esse inclusive apresentado na página da prefeitura da cidade de Foz do Iguaçu.

Figura 2 - printscreen da página oficial da Prefeitura Municipal de Foz do Iguaçu

\footnotetext{
${ }^{8}$ As perguntas do questionário eram:

1. Para você, o que é morar na fronteira?

2. Com que frequência você vai para os países vizinhos?

3. Tem amigos/conhecidos/familiares argentinos e/ou paraguaios?

4. Você conhece ou usa palavras em espanhol ou guarani no seu dia a dia? Quais? E em que ocasiões?

5. Como você definiria/descreveria o argentino?

6. Como você definiria/descreveria o paraguaio?

7. Você acha que a maioria dos argentinos são como você descreveu?

8. Você acha que a maioria dos paraguaios são como você descreveu?

9. Você tem alunos de outras nacionalidades ou que falam uma língua diferente do português na sala de aula? Como lida com isso?
} 


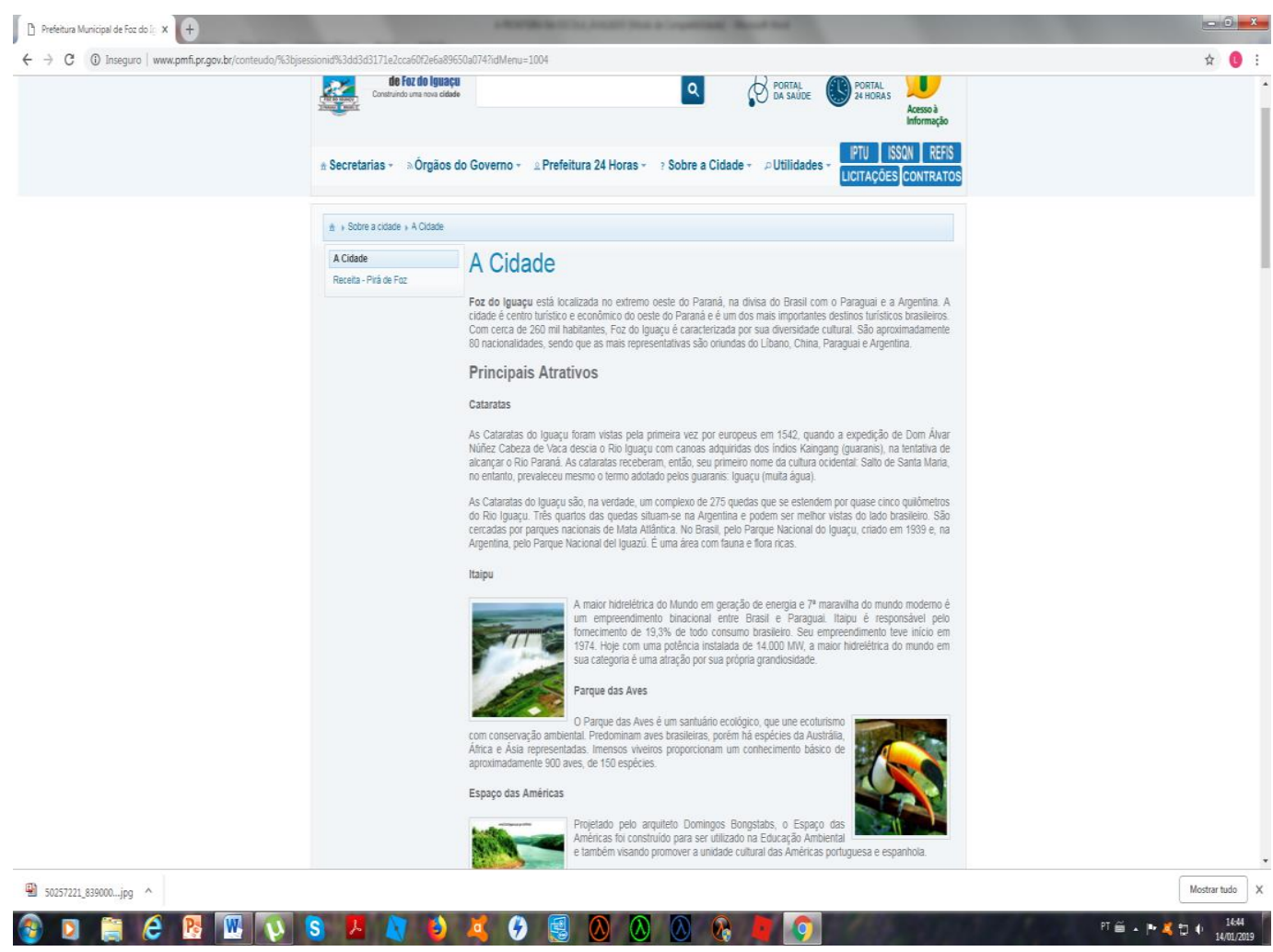

Fonte: http://www.pmfi.pr.gov.br/conteudo/\%3bjsessionid\%3dd3d3171e2cca60f2e6a89650a074?idMenu=1004 Acesso em novembro de 2018.

Sobressai-se, portanto, a ideia de fronteira como uma região em que se coabitam e convivem diferentes culturas e línguas, tal como apresentado no discurso do governo. Além disso, salientava-se como um lugar idílico, focando na importância e quão afortunadas são as pessoas em coabitar um espaço permeado por diversas culturas fixas (argentina e paraguaia), como as de passagem (turistas e as diversas etnias sempre citadas em noticiários). Analisando os questionários, aos poucos a diversidade começa a ser mencionada e percebida exclusivamente na distinção das línguas e das culturas, ou seja, Foz do Iguaçu é uma cidade permeada de línguas e culturas diferentes, e isso é bom. Mas fica a dúvida: até que ponto essas línguas e culturas diferentes são de fato integrados no dia a dia dos habitantes deste território? Ou essas línguas e culturas só ficam presas em outdoors ou placas de informação para turistas?

Mas quando tratamos sobre questões de sala de aula, essa diversidade é vista como algo natural e que não deve ser um diferencial a ser destacado - tal como é feito na propaganda sobre a cidade. Muitas professoras responderam que "procuro[am] agir com naturalidade e tento[am] acolhê-los”, mas agir com naturalidade, a partir da nossa observação e em conversas informais pela escola, é o mesmo que não se considerar as diferenças na (trans)formação do cotidiano. Tal como salienta Santos (2003, p. 56): 
Temos o direito a ser iguais quando a nossa diferença nos inferioriza; e temos o direito a ser diferentes quando a nossa igualdade nos descaracteriza. Daí a necessidade de uma igualdade que reconheça as diferenças e de uma diferença que não produza, alimente ou reproduza as desigualdades.

Assim vemos a repetição do discurso pedagógico da homogeneidade e do tratamento igual para todas as crianças, mas esse discurso apaga a diversidade e não potencializa o sujeito. Desta forma, o que vemos é uma repetição de práticas e discursos, em um ambiente que deveria, por sua natureza geográfica, promover e discutir o diferente e a diferença.

Existe um plano de ensino, uma história a ser ensinada, uma língua a ser ensinada. A orientação multiculturalista ${ }^{9}$ prevalece no dia a dia escolar, onde, embora se saiba que existam várias culturas, há uma que prevalece institucionalizada no poder como sendo a legítima.

A nocividade desta perspectiva posta em prática se dá, por vezes, no ocultar da singularidade de determinadas/os sujeitas/os. Uma das pessoas entrevistadas, por exemplo, relata que acredita não existir diferenças entre brasileiros, argentinos e paraguaios. Em resposta à questão 5 , ela nos diz "Não vejo diferença entre nós", e em resposta à pergunta 6 , "Como nós brasileiros".

Embora o espaço perceptivelmente esteja marcado por diversas culturas, suas práticas e realidades históricas, a negação da diferença e da valorização dessa característica é uma marca presente. Entende-se que essa negação é um ato de violência contra a existência do outro. Para essas professoras e professores o papel da escola acaba por ser o de neutralizar as diferenças, apaziguando superficialmente as contradições e conflitos que existem entre os corpos que compõem a região. Prejudicando, a potencialidade do espaço escolar "na direção da desconstrução de subalternidades ou a emergência de outros efeitos de sujeito e outros regimes de verdade" (AZIBEIRO; FLEURI, 2012, p. 221).

A escola de e na fronteira aparenta se conceber como aquela que tem o desafio de suportar, adaptar e moldar a diferença. Viver e trabalhar na fronteira são, portanto, estar indissociável da lógica do poder vigente. Embora algumas respostas relatem ainda, que entrevistadas/os têm familiares nos países tão próximos, o ir e vir é pouco praticado. A tensão entre o macro e o micro afeta o imaginário que se tem do outro. A escola, o currículo e nós,

\footnotetext{
9 “El multiculturalismo sustenta la producción y administración de la diferencia dentro del orden nacional volviéndola funcional a la expansión del neoliberalismo" (WALSH, 2008, p. 141).
} 
somos reflexo das imposições, consciente ou inconscientemente, da nossa sociedade como um todo.

\section{Conclusão primária}

Como franjas de uma cortina que se tocam quando balançadas pelo vento, cada cultura mantém-se presa à sua parte e a seu grupo, ao mesmo tempo em que é tocada pelo contato com outro grupo étnico. Como franjas que, ao sabor do vento, se aproximam, se distanciam, se entrelaçam, as culturas, dependendo do contexto histórico, interpenetram-se, entrelaçam-se, aproximando-se ou distanciando-se (GRANDO, 2004 apud AZIBEIRO; FLEURI, 2012, p. 227).

Morar em uma fronteira nos leva a ver as relações cotidianas como algo híbrido que supera as demarcações geográficas impostas por mapas físicos. A fronteira acaba sendo um "problema", pois não é um território binário, mas um grande fluxo de histórias e pensamentos, desvinculados de qualquer discurso identitário único preestabelecido por uma suposta soberania nacional.

Pensar a educação e sujeitos/as educacionais deste espaço, poderia nos auxiliar a compreender a problematização feita na formação identitária do ser trifronteiriço. Acreditase que o ambiente escolar é um local propício para a manutenção ou para a desconstrução de vários estereótipos e discursos; assim podemos analisar o quanto a educação pode corroborar ou não na formação de um sujeito disposto a $[\operatorname{des}($ re $)]$ construir sua própria identidade a partir do discurso de e sobre o Outro. Com base nos dados obtidos, pudemos perceber que as narrativas educacionais (documentos oficiais e entrevistas com docentes) refuta uma visão desconstrutivista desse espaço educacional, salientando as diferenças.

Neste trabalho, consideramos que as práticas discursivas auxiliam na formação e construção do imaginário e focando no discurso educacional como um dos itens na formação da identidade e também do próprio imaginário. Desta forma, urge repensar uma formação educacional (tanto de docentes, quanto de gestores/as) própria na e para à fronteira, que respeite e contemple a diversidade e a multiterritorialidade.

\section{Referências}

ADICHIE, C. N. Para educar crianças feministas. Tradução: Denise Bottmann. Companhia das Letras, 2017. 
AZIBEIRO, N. E.; FLEURI, R. M. Paradigmas culturais emergentes na educação popular. In: DANTAS, S. D. Diálogos Interculturais: Reflexões Interdisciplinares e Intervenções Psicossociais. São Paulo, Instituto de Estudos Avançados da Universidade de São Paulo, p. $219-246,2012$.

CANDAU, V. M. F.; OLIVEIRA, L. F. Pedagogia Decolonial e educação anti-racista e intercultural no Brasil. Educação em Revista (UFMG. Impresso), v. 26, p. 15-40, 2010.

CARVALHO, F. O. . ¡Hola!, Qué tal?. In: Mirian Celeste Martins. (Org.). Pensar juntos mediação cultural: [entre]laçando experiências e conceitos. 1ed. São Paulo: Terracota, 2014 a, v., p. 31-33.

CARVALHO, F. O. O conceito de interculturalidade e a mediação cultural na escola. In: Mirian Celeste Martins. (Org.). Pensar juntos mediação cultural: [entre]laçando experiências e conceitos. 1ed. São Paulo: Terracota, 2014, v., p. 109-116.

CHAUÍ, M. Janela da alma, espelho do mundo. O olhar. São Paulo: Companhia das letras, v. 495, 1988.

CONCEIÇÃO, J. P. Aprender a viver juntos: Ensino de História e Educação Intercultural In: Ensino de História: Memória e Identidade. 1 ed. Jundiaí: Paço Editorial, 2016, v.1, p. 155-170.

DIAS, M. de F. S.. História da América: ensino, poder e identidade. Letras Contemporâneas, 2004.

FANON, F. Pele negra, máscaras brancas. Salvador: EDUFBA, 2008.

GUSMÃO, N. M. M. de. Linguagem, cultura e alteridade: imagens do outro. Faculdade de Educação da UNICAMP. Cadernos de pesquisa, n 107, p. 41 - 78. Julho/1999.

HAESBART, R. Da desterritorialização à multiterritorialidade, Boletim Gaúcho de Geografia, 29: 11-24, jan., 2003.

LAKATOS, Eva Maria; MARCONI, Marina de Andrade. Fundamentos de metodologia científica. São Paulo: Atlas 2003.

LOURO, G. L. . Teoria queer - uma política pós-identitária para a educação. Revista Estudos Feministas, Florianópolis, v. 9, n.2, p. 541-553, 2001.

MACEDO, E. Currículo: política, cultura e poder. Currículo sem fronteiras. 6.2 (2006): 98-113.

MACEDO, E. A Cultura e a Escola. Marcas da diferença no ensino escolar. São Carlos: EdUFSCar, 2010.

MEDEIROS, R. M. V. . Território, espaço de identidade. In: SAQUET, Marcos Aurélio; SPOSITO, Eliseu Savério. (Org.). Territórios e territorialidades - teorias, processos e conflitos. São Paulo: Expressão Popular, 2009. 
MIGNOLO, W. D. Bilinguajando o amor: pensando entre línguas. In: Histórias locais/Projetos globais: colonialidade, saberes subalternos e pensamento liminar. Belo Horizonte: Editora da UFMG, 2003.

MYSKIW, A. M. A fronteira como destino de viagem: a colônia militar de Foz do Iguaçu (1888/1907). UNICENTRO, p. 33-73, 2011.

OLIVEIRA, N. R. O. de. Foz do Iguaçu intercultural: cotidiano e narrativas da alteridade. 2012.

PARASKEVA, J. M. Michael W. Apple e os estudos [curriculares] críticos. Currículo sem Fronteiras, v. 2, n. 1, p. 106-120, 2002.

SANTOS, B. de S.. Reconhecer para libertar: os caminhos do cosmopolitanismo multicultural. Rio de Janeiro: Civilização Brasileira, 2003.

TAVARES, Manuel. Epistemologias do Sul. Rev. Lusófona de Educação, Lisboa, n. 13, p. 183-189, 2009. Disponível em $\leq \mathrm{http}: / /$ www.scielo.mec.pt/scielo.php?script=sci arttext\&pid=S1645-

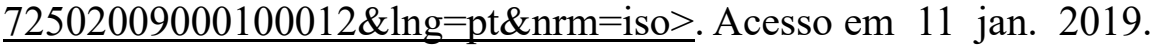

UNILA. Programa Escolas Interculturais de Fronteira. 2016. Disponível em: $<$ https://www.unila.edu.br/es/node/5086>. Acesso em 02 de out. 2017.

WALSH, C. Interculturalidade crítica e pedagogia decolonial: in-surgir, re-existir e re-viver. In: _. Educação intercultural na América Latina: entre concepções, tensões e propostas. Rio de Janeiro, v. 7, p. 12-42, 2009.

WALSH, C. Interculturalidad, plurinacionalidad y decolonialidad: las insurgencias político-epistémicas de refundar el Estado. Tabula rasa, n. 9, p. 131-152, 2008. 